\title{
Overestimation of the second time interval replaces time-shrinking when the difference between two adjacent time intervals increases
}

\author{
Yoshitaka Nakajima ${ }^{1}$, Emi Hasuo ${ }^{2}$, Miki Yamashita $^{3}$ and Yuki Haraguchi ${ }^{4}$ \\ ' Department of Human Science, Research Center for Applied Perceptual Science, Kyushu University, Fukuoka, Japan \\ 2 Japan Society for the Promotion of Science/Neurological Institute, Kyushu University, Fukuoka, Japan \\ ${ }^{3}$ Kyushu Institute of Design, Fukuoka, Japan \\ ${ }^{4}$ Department of Acoustic Design, Kyushu University, Fukuoka, Japan
}

\section{Edited by:}

Willy Wong, University of Toronto, Canada

\section{Reviewed by:}

Willy Wong, University of Toronto,

Canada

Simon Grondin, Université Laval,

Canada

\section{*Correspondence:}

Yoshitaka Nakajima, Department of Human Science, Research Center for Applied Perceptual Science, Kyushu University, 4-9-1 Shiobaru, Minami-ku, Fukuoka 815-8540, Japan

e-mail:nakajima@

design.kyushu-u.ac.jp
When the onsets of three successive sound bursts mark two adjacent time intervals, the second time interval can be underestimated when it is physically longer than the first time interval by up to $100 \mathrm{~ms}$. This illusion, time-shrinking, is very stable when the first time interval is $200 \mathrm{~ms}$ or shorter (Nakajima etal., 2004, Perception, 33). Time-shrinking had been considered a kind of perceptual assimilation to make the first and the second time interval more similar to each other. Here we investigated whether the underestimation of the second time interval was replaced by an overestimation if the physical difference between the neighboring time intervals was too large for the assimilation to take place; this was a typical situation in which a perceptual contrast could be expected. Three experiments to measure the overestimation/underestimation of the second time interval by the method of adjustment were conducted. The first time interval was varied from 40 to $280 \mathrm{~ms}$, and such overestimations indeed took place when the first time interval was 80-280 ms. The overestimations were robust when the second time interval was longer than the first time interval by $240 \mathrm{~ms}$ or more, and the magnitude of the overestimation was larger than $100 \mathrm{~ms}$ in some conditions. Thus, a perceptual contrast to replace time-shrinking was established. An additional experiment indicated that this contrast did not affect the perception of the first time interval substantially: The contrast in the present conditions seemed unilateral.

Keywords: time perception, assimilation, contrast, audition, time-shrinking, empty interval

\section{INTRODUCTION}

When the onsets of three successive sound bursts mark two neighboring time intervals, the second time interval can be underestimated when it is longer than the first time interval by up to 100 ms. This underestimation, i.e., time-shrinking, is very stable when the first time interval is $200 \mathrm{~ms}$ or shorter (Nakajima et al., 1991, 2004), and has been considered a kind of perceptual assimilation. Assimilation and contrast in perceptual paradigms often replace each other when the relationship and configuration of stimuli are changed systematically (e.g., Helson, 1963; Morinaga and Noguchi, 1966).

Assimilation and contrast may not necessarily be governed by a single perceptual mechanism, but they are likely to work under one perceptual principle for humans and animals to process information from the environment efficiently and quickly. For example, a figure in which luminance is sufficiently higher than in the background can be distinguished clearly from the background in the visual modality. This process is enhanced by contrast, which enlarges the perceptual difference in terms of lightness or color between the figure and the background, as well as by assimilation, which homogenizes the lightness or color within the figure and within the background (Koffka, 1935; Shapley and Reid, 1985). It is also argued that, when two potential objects are separated enough spatially from each other (but within a distance to keep a mutual interaction), they are likely to be organized as two separate wholes which are then contrasted (King, 1988). It is widely observed that perceptual assimilation between objects gives way to contrast when the difference between these objects is increased, and that assimilation can be blocked if the area or the group to be assimilated is broken by a boundary (or boundaries; e.g., Koffka, 1935; Hamburger, 2005), or by a temporal distance (Ikeda and Obonai, 1955). In Ikeda and Obonai's (1955) experiment, concentric circles with different diameters $I$ and $T$ were presented simultaneously for $500 \mathrm{~ms}$ using a tachistoscope. The diameter of $T$, whose size was to be judged, was fixed at $30 \mathrm{~mm}$. When the physical size of $I$ was similar to that of $T$, assimilation took place, but contrast took over when the physical size difference was larger (Table 1). The fact that assimilation and contrast can both take place in the same experimental context is described systematically by Helson (1964). One should note that temporal configurations of stimuli can also lead to an assimilation or contrast of the stimuli (Shigeno, 1991; see also McKenna, 1984). In our study, assimilation and contrast were manipulated through modifying the temporal configuration of the sound bursts.

When the difference between close but distinguishable objects or events is small, the objects will be seen as part of a homogeneous group. If the difference cannot be neglected, the objects or events 
Table 1 | Underestimation and overestimation of the size of a circle, $T=\mathbf{3 0} \mathbf{m m}$, caused by another concentric circle, $I$, as observed by Ikeda and Obonai (1955).

\begin{tabular}{lcccccc}
\hline Diameter of $T$ & \multicolumn{7}{c}{$\mathbf{3 0}$} \\
\cline { 2 - 7 } Diameter of $\boldsymbol{I}$ & $\mathbf{1 0}$ & $\mathbf{1 5}$ & $\mathbf{2 0}$ & $\mathbf{4 0}$ & $\mathbf{6 0}$ & $\mathbf{8 0}$ \\
\hline Overestimation of $T$ & +1.2 & -0.7 & -1.4 & +0.6 & +0.3 & -0.5 \\
& C & A & A & A & A & C \\
\hline
\end{tabular}

The values are in millimeters. $A$, assimilation; $C$, contrast.

will instead be perceived in different categories. This is the case particularly for the human auditory modality, which is responsible for quick and complicated communication sometimes in noisy environments without favorable acoustics.

Linguistic communication depends on the human capacity to process strings of categorized elements in time. This requires that any pair of sounds or sound patterns should be clearly either the same or different (de Saussure, 1966); assimilation and contrast must work for the listener to decode speech signals properly (e.g., Shigeno, 1991). Temporal aspects of auditory perception are also very likely to work in the same manner. Relative lengths of syllables are categorized in many languages; it is often important for the listener to judge, without hesitation, whether or not one of two neighboring syllables is longer or shorter than the other. When time intervals are presented in concatenation, listeners often simplify the patterns reducing small differences, and exaggerating larger differences (e.g., Fraisse, 1978, 1982; Povel, 1981). A ratio 1:2 or 2:1 seems stable perceptually, which means that the second time interval is likely to be overestimated if the neighboring time intervals are to be perceived as in a ratio 1:1.7 or 1:1.8 otherwise. We were interested in whether the extremely stable illusion of time-shrinking, a unilateral assimilation of a time interval to a preceding time interval or preceding time intervals, could be grasped in relation to such opposite perceptual processes. We thus examined whether a time interval was contrasted, instead of assimilated, to a preceding time interval at a certain point when the difference between these adjacent time intervals was increased step by step. When two adjacent empty time intervals $t_{\mathrm{P}}$ and $t_{\mathrm{S}}$ were presented in this order in our previous research, the same tp may have caused both underestimation and overestimation of $t_{\mathrm{S}}$ depending on the physical difference between $t_{\mathrm{p}}$ and ts. Nakajima et al.'s (2004) experiments suggested that this possibility is systematic. Table 2 indicates the cases in which both underestimation and overestimation reached $20 \mathrm{~ms}$ for a fixed $t_{\mathrm{p}}$ value.

The present paradigm thus became clear. Time-shrinking typically takes place when two time intervals, $t_{\mathrm{p}}$ and $t_{\mathrm{S}}$ in this order, marked by the onsets of three successive sound bursts meet the following conditions: $0<t_{\mathrm{S}}-t_{\mathrm{P}} \leq 80 \mathrm{~ms}$, and $t_{\mathrm{p}} \leq 200 \mathrm{~ms}$. It had been indicated already that overestimation of $t_{\mathrm{S}}$ to exaggerate the difference between $t_{\mathrm{P}}$ and $t_{\mathrm{S}}$ could take place when the physical difference between the neighboring time intervals, $t_{\mathrm{S}}-t_{\mathrm{p}}$, exceeded the above range (Nakajima et al., 2004). This problem had never been taken up systematically. In order to reveal the mechanism
Table 2 | Temporal patterns in which time shrinking was replaced by overestimation in Nakajima et al. (2004).

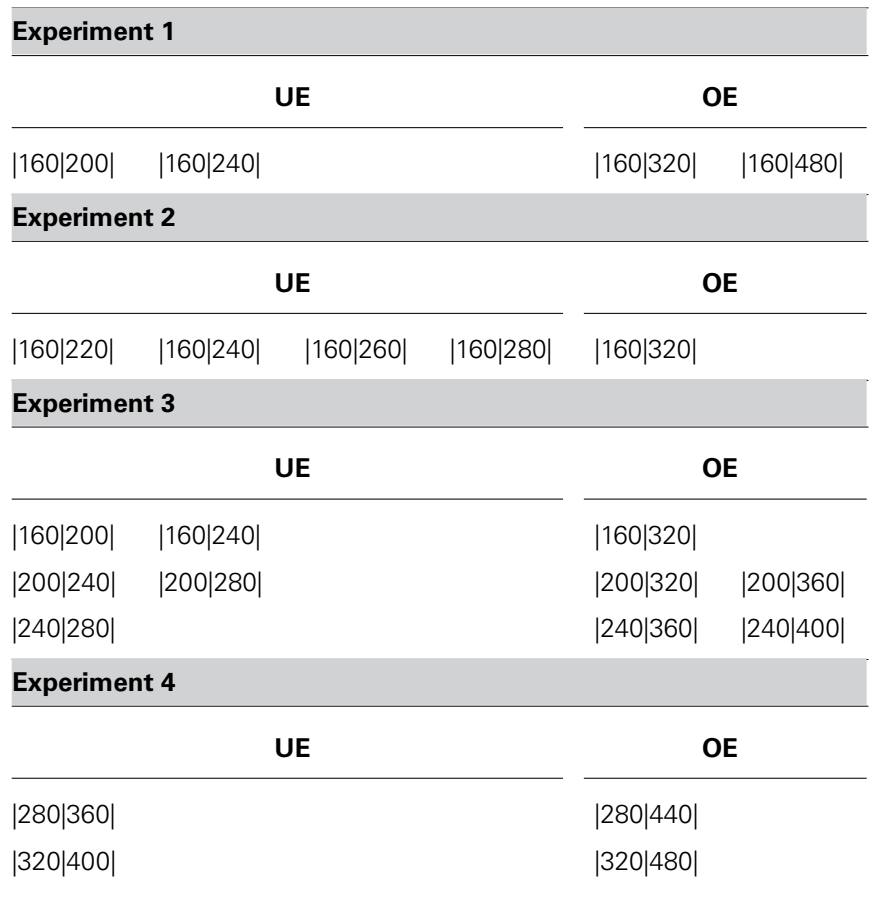

Both the underestimation of a standard time interval, i.e., time shrinking, and the overestimation of a longer standard appeared for the same preceding time interval in the stimulus conditions indicated in each line. The physical durations of two adjacent time intervals tp and ts are indicated as /t $/ t_{\mathrm{S}} /$ in milliseconds. The conditions in which the underestimation/overestimation was equal to or above 20 ms were taken up to specify these temporal patterns. UE, underestimation; $O E$, overestimation.

of rhythmic organization, however, it seemed of crucial importance to examine whether a systematic overestimation of $t_{\mathrm{S}}$ would replace the underestimation, which we call time-shrinking, if we increased the difference $t_{S}-t_{\mathrm{p}}$.

\section{GENERAL METHODS}

The general framework common to the present experiments is described in Figure 1. In the first three experiments, we basically followed the paradigm employed in previous studies on timeshrinking (e.g., Nakajima et al., 2004), except that we increased the range of the standard duration to be judged. In the control condition, a time interval, $t_{\mathrm{S}}$, marked by the onsets of two successive tone bursts was the standard to be judged. An additional tone burst preceded $t_{\mathrm{S}}$ in the experimental condition; the effect of the preceding time interval, $t_{\mathrm{p}}$, marked by the onsets of this additional tone burst and the first marker of $t_{S}$ was studied. The difference in subjective duration of $t_{S}$ between the control and the experimental condition was measured.

In the last experiment, Experiment 4, a tone burst did not precede but succeeded $t_{S}$, and the effect of the succeeding time interval, $t_{\text {SUC }}$, marked by the onsets of the second marker of $t_{S}$ and this additional tone burst was examined in order to interpret the results of the first three experiments. This was the experimental condition, and no control condition was employed because the data of the control condition in Experiment 3 could be reused. 


\section{Control condition (Experiments 1-3)}

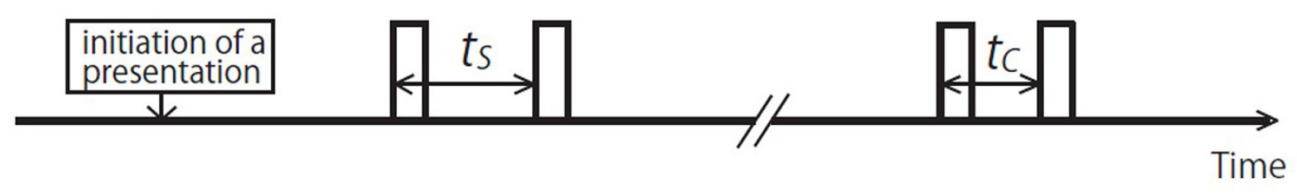

Experimental condition (Experiments 1-3)

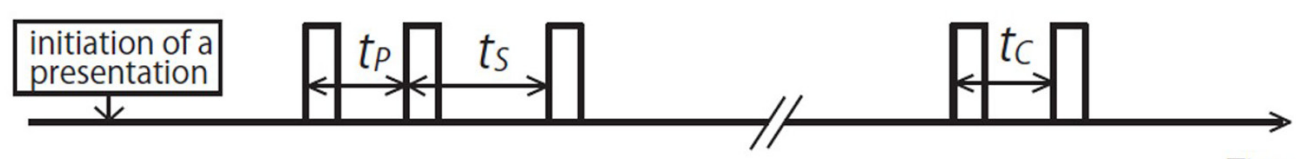

Time

Experimental condition (Experiment 4)

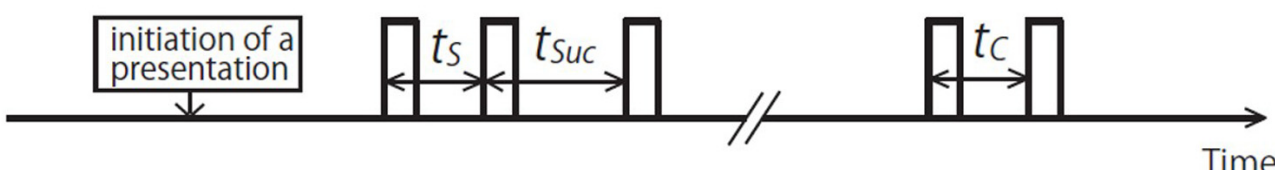

FIGURE 1 |Time charts of stimulus patterns. The rectangles represent sounds. In the experiments, participants adjusted $t_{C}$ to make its subjective duration equal to that of $t_{S}$. In the experimental conditions of Experiments
$1-3, t_{\mathrm{P}}$ was added before $t_{S}$. In the experimental condition of Experiment

$4, t_{S U C}$ was added after $t_{S}$. Note that all time intervals $\left(t_{S}, t_{\mathrm{P}}, t_{S} \cup \mathrm{c}\right.$, and $\left.t_{C}\right)$ refer to the duration between the onsets of successive sounds.
The method of adjustment was employed. The participant initiated each presentation by clicking a pane on the computer screen. A few seconds - the interval was chosen randomly within a range - after the clicking, the first tone burst of the standard pattern $t_{\mathrm{S}}, t_{\mathrm{P}} \mid t_{\mathrm{S}}$, or $t_{\mathrm{S}} \mid t_{\mathrm{SUC}}$ was presented. After that, there was a period of a few seconds - the interval was again chosen randomly, and then, another time interval, the comparison, $t_{C}$, was presented with the onsets of two successive tone bursts. The task of the participant was to adjust $t_{C}$ to make it equal to $t_{S}$ in subjective duration. The participant could change $t_{C}$ by operating a screen interface, designed in a way not to give a visual hint about the present duration, and the minimum step of the adjustment was $1 \mathrm{~ms}$. The participant was allowed to listen to the whole sequence as many times as he/she needed until $t_{S}$ and $t_{C}$ were perceived as equal, and finished the trial when satisfied. The last $t_{C}$ value was recorded as the point of subjective equality, PSE.

\section{EXPERIMENT 1}

This experiment was conducted in 1996. Because we did not have an institutional ethical committee for psychological experiments at that time, an internal ethical review was impossible, but the experiment was a part of a research project reviewed by a governmental committee to select projects to be funded (as in the acknowledgments). This experiment is included in the present report because this was the first case in which the perceptual phenomenon we are going to describe appeared systematically. Our original purpose had been to determine the stimulus conditions to investigate the effect of sound marker duration on the occurrence of time-shrinking (underestimation), for there was a possibility that the amount of time-shrinking may be reduced, or the time condition for maximum time-shrinking could be shifted, by lengthening the markers (see Hasuo et al., 2011). From the present viewpoint, however, the experimental data gave us insight into the possibility of systematic overestimation of the second of two adjacent time intervals. The same $t_{\mathrm{S}}$ values were employed with a $t_{\mathrm{P}}$ in the experimental condition and in isolation in the control condition. The PSEs in these conditions were compared to see the amount of perceptual overestimation or underestimation of $t_{\mathrm{S}}$ caused by $t_{\mathrm{P}}$.

\section{METHODS \\ Participants}

The participants were five students, i.e., three males and two females, of the Kyushu Institute of Design (the predecessor of the Faculty of Design, Kyushu University). They had received education for acoustic design, including basic training in music performance. They were 20-24 years old, and had normal hearing.

\section{Materials}

Duration markers were pure tone bursts of $1000 \mathrm{~Hz}$ and 12, 63, or $123 \mathrm{~ms}$ with a rise and a fall time of $\sim 2 \mathrm{~ms}$ each. These values were inexact due to our use of an analog filter to shape the 
waveform; the inexactness was sufficiently small relative to the effect we were measuring. The tone bursts of different durations were approximately equal in loudness when presented separately. This was realized by conducting preliminary measurements in which the participant could listen to any of the three sounds by clicking corresponding buttons on the computer screen. The stimulus sound was presented always $200 \mathrm{~ms}$ after the button was clicked. The level of the 12-ms burst, which was very short, was fixed at $97 \mathrm{dBA}$ as defined as the level of a continuous tone of the same amplitude measured with an artificial ear (Brüel and Kjær 4153), a microphone (Brüel and Kjær 4134), and a sound level meter (Brüel and Kjær 2209). The levels of the other sounds were adjustable, and the participant was instructed to equalize the three sounds in terms of loudness. In each trial, the adjusted levels of the 63 and 123 ms bursts were recorded. The participant performed eight trials, and the median value for each sound was employed as the presentation level in the main part of the experiment. The presentation levels were 87$94 \mathrm{dBA}$ for the 63-ms burst, and 85-93 dBA for the 123-ms burst.

The pure tones were first generated as rectangular pulse series before being band-pass filtered between 850 and $1250 \mathrm{~Hz}$ (NF DV-6BW). This resulted in tone bursts with rise and fall times of $\sim 2 \mathrm{~ms}$. The tone bursts were presented to the left ear of the participant through an amplifier (JVC AX-Z511) and headphones (AKG K141) in a soundproof room. The experimental procedure including stimulus generation was controlled by a quiet computer without a hard disk drive or a fan (Commodore Amiga 500).

In the main part of the experiment, the marker duration was fixed in each standard pattern, which was marked by two or three successive tone bursts, and the comparison time interval was always marked by two 12-ms tone bursts. In the standard patterns of the experimental condition, $t_{\mathrm{p}} \mid t_{\mathrm{S}}$, the preceding time interval, $t_{\mathrm{P}}$, was fixed at $160 \mathrm{~ms}$. Both in the control and in the experimental condition, the standard time interval, $t_{S}$, was varied from 120 to $440 \mathrm{~ms}$ in steps of $40 \mathrm{~ms}$. The $t_{\mathrm{S}}$ duration of $120 \mathrm{~ms}$ was not possible when the marker duration was longer, i.e., $123 \mathrm{~ms}$; this condition was omitted. Thus, there were 58 stimulus patterns: [2 (control/experimental) $\times 2$ (marker durations $\leq 63 \mathrm{~ms}) \times 10$ $\left(t_{\mathrm{S}}\right.$ durations $)+1$ (marker duration $\left.=123 \mathrm{~ms}\right) \times 9\left(t_{\mathrm{S}}\right.$ durations)]. The standard pattern was presented 2300-2500 ms after the participant clicked a button on the screen. There was a silence of 2700-3300 ms between the offset of the last sound marker of $t_{\mathrm{S}}$, and the onset of the first sound marker of $t_{\mathrm{C}}$.

\section{Procedure}

The participant performed four adjustment trials, two in ascending series and two in descending series, for each stimulus pattern: two replications for both series were performed. One replication comprised the first half, and the other the second half of the whole measurement. Each replication (= half) consisted of 116 trials, 58 (stimulus patterns) $\times 2$ (series) in random order, and was divided into 9 blocks of 12 or 13 measurement trials, which were preceded by two warm-up trials. Preceding the measurement, the participant performed 58 training trials, divided into four blocks; each stimulus pattern appeared once. Thus, the whole experiment consisted of 22 blocks: 4 (training blocks) +2 (replications) x 9 (measurement blocks). Each block took around 15-20 min, and the whole experiment was carried out over a period of 8 days for each participant.

\section{RESULTS AND DISCUSSION}

We performed a three-way [marker duration $\times$ condition (experimental/control $) \times t_{\text {S }}$ duration] ANOVA utilizing the PSEs for $t_{\mathrm{S}}=160-480 \mathrm{~ms}$. Since it is commonplace that PSEs change as $t_{S}$ changes, we will not detail the main effect of this factor neither here nor in the following experiments; its main effect was always significant $(p<0.001)$. The main effect of marker duration was significant, $F(2,8)=21.902, p<0.01, \eta_{\mathrm{p}}^{2}=0.846$. Ryan's post hoc test showed that the difference between all combinations of marker duration, i.e., 12 and 123; 63 and 123; and 12 and $63 \mathrm{~ms}$; was significant $(p<0.05)$. The interaction between condition (experimental/control) and ts duration was also significant, $F(8,32)=4.614, p<0.01, \eta_{\mathrm{p}}^{2}=0.536$. This interaction should be related to the assimilation and contrast of $t_{\mathrm{S}}$ to $t_{\mathrm{p}}$. The main effect of condition (experimental/control) and the other interactions were not significant $(p>0.05)$.

The PSEs in the control condition were very close to the physical values of $t_{\mathrm{S}}$ (Figure 2). Slight deviations appeared systematically, however: PSEs of shorter duration tended to be longer than the physical values of $t_{\mathrm{S}}$. This kind of time errors sometimes appear in the literature of time perception (Woodrow, 1951; Eisler et al., 2008). The PSEs tended to be slightly longer when the marker duration was longer, but the present data do not offer much information on this issue. This issue should be investigated intensively in the future in order to understand rhythm perception in speech or music. Hasuo et al. $(2011,2012)$ reported that inter-onset time intervals up to $360 \mathrm{~ms}$ tended to be perceived as longer when the duration of the sound markers to terminate the time intervals were longer. This was the case whether the time interval to be judged was isolated or neighboring another time interval. The duration of the sound markers to initiate the time intervals showed similar effects, but in a more unstable manner.

The PSEs in the control and in the experimental condition differed systematically. The experimental PSEs were smaller than the corresponding control PSEs when $t_{\mathrm{S}}=200$ or $240 \mathrm{~ms}$, i.e., when $t_{\mathrm{S}}-t_{\mathrm{P}}=40$ or $80 \mathrm{~ms}$ : $t_{\mathrm{S}}$ was underestimated showing timeshrinking in a typical manner. However, the difference between the control and the experimental condition was reversed when $t_{S}$ was longer: the experimental PSEs were systematically greater than the control PSEs when $t_{\mathrm{S}} \geq 320 \mathrm{~ms}$. Thus, time-shrinking as assimilation of $t_{\mathrm{S}}$ to $t_{\mathrm{P}}$ appeared when the difference between these neighboring time intervals was small, and gave way to contrast of $t_{\mathrm{S}}$ to $t_{\mathrm{P}}$ when the difference was large.

The above tendency appeared in similar ways in all the marker conditions between the control and the experimental PSEs despite the fact that the control PSEs increased slightly, but clearly, if the sound marker duration was increased. The contrast appeared as overestimation of $t_{\mathrm{S}}$ in the experimental condition against the control condition. The PSEs were already lengthened in the control condition if the sound markers were longer, and they became even longer - were overestimated further - in the experimental condition. Furthermore, the amount of overestimation was larger when the duration markers were longer. This is in contrast with 


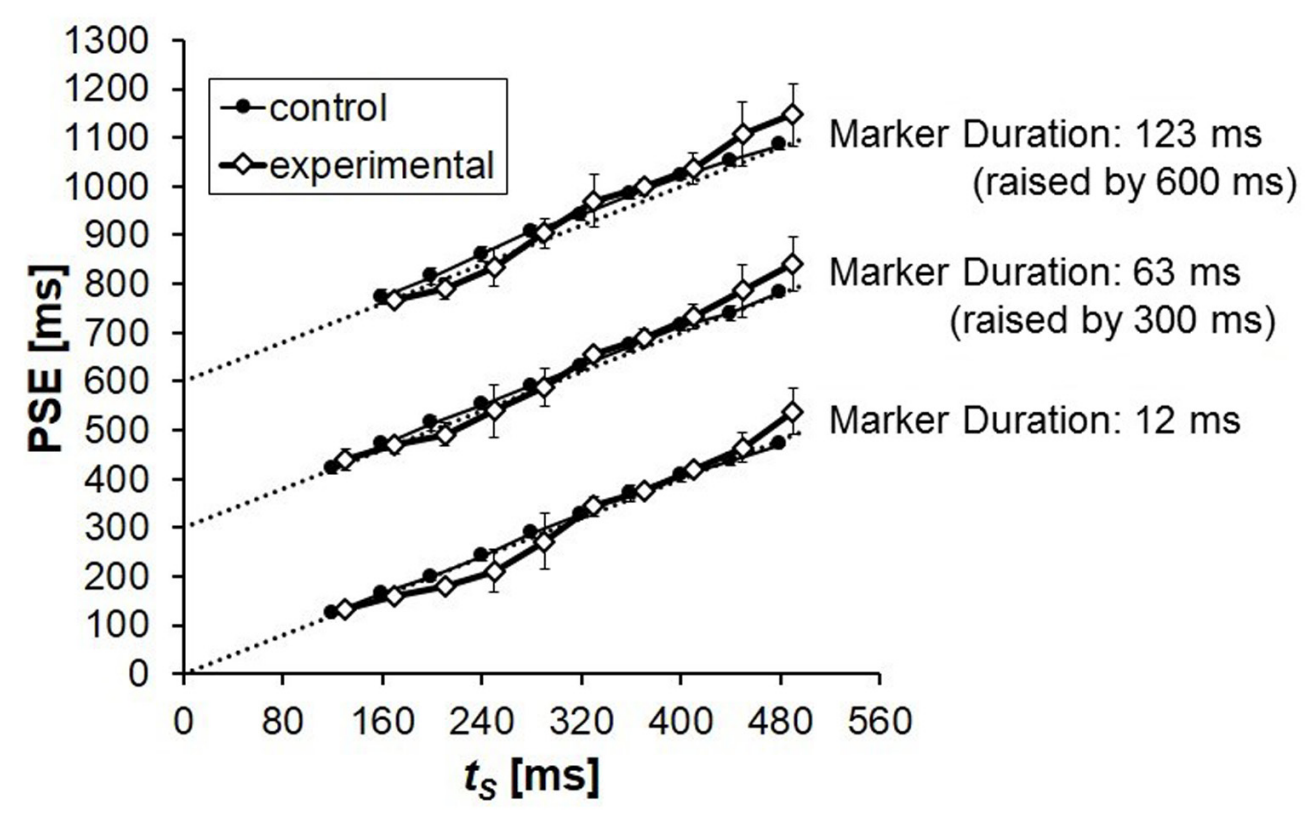

FIGURE 2 | Mean PSEs obtained from five participants in Experiment 1. PSE corresponds to the duration of $t_{C}$ that was perceived to be equal to the duration of $t_{S}$. The results for marker durations 63 and $123 \mathrm{~ms}$ were raised by
300 and $600 \mathrm{~ms}$, respectively, in this graph for clarity. The physical values of $t_{S}$ (the points of objective equality) are indicated by dotted lines. Error bars represent standard deviations between participants. the fact that the magnitude of time-shrinking - underestimation is often smaller when longer markers are used (Yamashita and Nakajima, 1999; Hasuo et al., 2011), as was the case also in the present experiment.

The overestimation, as represented by the difference in the PSEs between the control and the experimental condition, seemed to have a local peak when $t_{\mathrm{S}}=320 \mathrm{~ms}$ for all the marker durations. This tendency was peculiar and robust, but we leave this issue for future research.

To test whether the common tendency in overestimation pattern (i.e., the difference between the control and the experimental PSEs over the $t_{S}$ duration range) across different marker durations was statistically significant, we conducted a Friedman test (e.g., Siegel and Castellan, 1988) utilizing the mean overestimation values for each marker duration. There was a statistically significant tendency in overestimation, $\chi^{2}(8)=23.644, p=0.003$. To examine whether the overestimation patterns had a common tendency even when the influence of time-shrinking (the negative overestimation at $t_{\mathrm{S}}-t_{\mathrm{P}}=40$ or $80 \mathrm{~ms}$ ) was cancelled, we also performed the same Friedman test without the conditions in which $t_{\mathrm{S}}-t_{\mathrm{P}}=40$ or $80 \mathrm{~ms}$. The tendency in overestimation pattern was significant again, $\chi^{2}(6)=17.714, p=0.007$. The statistical significance in this additional Friedman test confirmed that the overestimation patterns had a common tendency even without the influence of time-shrinking.

\section{EXPERIMENT 2}

Experiments 2-4 were part of a research project approved by the research ethics committee of the Faculty of Design, Kyushu University, in 2010. Experiment 1 and our previous data on time-shrinking (e.g., Nakajima etal., 2004) revealed that the underestimation of a time interval that appeared as assimilation of $t_{\mathrm{S}}$ to $t_{\mathrm{P}}$ often gave way to contrast when $t_{\mathrm{S}}-t_{\mathrm{P}}>120 \mathrm{~ms}$. Because we did not have systematic data indicating this effect except in Experiment 1, we decided to conduct an experiment in which $t_{\mathrm{S}}$ was varied in a larger range (up to $640 \mathrm{~ms}$ ). For $t_{\mathrm{P}}$, we chose three values: 80, 120, and $160 \mathrm{~ms}$. Time-shrinking appears most stably in this range of $t_{\mathrm{p}}$ (Nakajima et al., 2004; Miyauchi and Nakajima, 2005), and we first needed experimental data under such conditions. One of the things we were interested in was whether any overestimation would appear for $t_{\mathrm{P}}=120 \mathrm{~ms}$; there had been occasional cases in previous data in which $t_{S}$ had been overestimated for $t_{\mathrm{P}}=80$ or $160 \mathrm{~ms}$, but no such cases ever for $t_{\mathrm{P}}=120 \mathrm{~ms}$. Most importantly, we wanted to see whether the typical time-shrinking, which was expected reliably if $t_{\mathrm{S}}-t_{\mathrm{P}}=40$ or $80 \mathrm{~ms}$, would give way to contrast, i.e., overestimation of $t_{\mathrm{s}}$.

\section{METHODS}

\section{Participants}

Five students of Kyushu University, three males and two females, participated. One of them had been educated to become a highschool music teacher, and three of them had received education for acoustic design, including basic training in music performance. The fifth one was an amateur musician who had been playing percussions for 8 years. They were $21-46$ years old.

\section{Materials}

Duration markers were pure tone bursts of $1000 \mathrm{~Hz}$ and $10 \mathrm{~ms}$ with cosine-shaped rise and fall times of $5 \mathrm{~ms}$ each, with no steady-state part. Their level was $80 \mathrm{dBA}$ as defined as the level of a continuous tone of the same amplitude measured with an artificial ear 
(Brüel and Kjær 4153), and a sound level meter (Node 2072 or 2075). The tone bursts were presented diotically to the participant through an amplifier (Stax SRM-323A) and headphones (Stax SR-303) in a soundproof room. The experimental procedure including stimulus generation was controlled by a computer (Frontier KZFM71/N) with an audio processor (Onkyo Wavio SE-U55GX). Stimulus patterns were generated digitally (16 bits; a sampling frequency of $44100 \mathrm{~Hz}$ ), and went through a $16-\mathrm{kHz}$ low-pass filter (NF DV-8FL) to avoid aliasing.

In the standard patterns of the experimental condition, $\left.t_{\mathrm{P}}\right|_{\mathrm{S}}$, the preceding time interval, $t_{\mathrm{p}}$, was 80,120 , or $160 \mathrm{~ms}$, for which time-shrinking had occurred typically in previous studies (e.g., Nakajima et al., 2004). Overestimation of $t_{S}$ had been recorded for $t_{\mathrm{P}}=80$ and $160 \mathrm{~ms}$, but only in a few stimulus patterns for each $t_{\mathrm{P}}$ value, and only up to $30 \mathrm{~ms}$, except for Experiment 1 of the present article. For $t_{\mathrm{P}}=120 \mathrm{~ms}$, no related measurements had been done before. The standard time interval, $t_{\mathrm{S}}$, was varied from 40 to $640 \mathrm{~ms}$ in steps of $40 \mathrm{~ms}$ both in the experimental and in the control condition. There were 64 stimulus patterns: 4 ( 1 control $+3 t_{\mathrm{P}}$ durations $) \times 16$ ( $t_{\mathrm{S}}$ durations $)$. The standard pattern was presented $1500-2500 \mathrm{~ms}$ after the participant initiated a presentation. There was an interval of 3000-4000 ms between the onsets of $t_{\mathrm{S}}$ and $t_{\mathrm{C}}$.

\section{Procedure}

The participant performed two adjustment trials, one in ascending series and one in descending series, for each stimulus pattern, and thus 128 trials in total: 64 (stimulus patterns) $\times 2$ (series), which were arranged in random order and divided into 11 blocks of 11 or 12 measurement trials preceded by two warm-up trials. Before the measurement, the participant performed one training session of 16 trials, for which representative stimulus patterns were employed. Thus, the whole experiment consisted of 12 blocks: 1 (training block) +11 (measurement blocks). Each block took around 15-30 $\mathrm{min}$, and the whole experiment was carried out over a period of 2-3 days for each participant.

\section{RESULTS AND DISCUSSION}

We performed a two-way [condition $\left(1\right.$ control $+3 t_{\mathrm{P}}$ durations $) \times t_{\mathrm{S}}$ duration] ANOVA utilizing the PSE values. The main effect of condition ( 1 control $+3 t_{\mathrm{p}}$ durations) was significant, $F(3,12)=8.624, p<0.01, \eta_{\mathrm{p}}^{2}=0.683$, and so was the interaction between condition ( 1 control $+3 t_{\mathrm{P}}$ durations) and $t_{\mathrm{S}}$ duration, $F(45,180)=3.344, p<0.01, \eta_{\mathrm{p}}^{2}=0.455$.

The PSEs in the control condition were close to the physical values of $t_{\mathrm{S}}$, but slight deviations appeared systematically (Figure 3 ). PSEs of longer duration tended to be longer than the physical values of $t_{\mathrm{S}}$, and this was not consistent with the tendency observed in Experiment 1. In both cases, however, the observed deviations were extremely small, and can be neglected for our present purpose.

The PSEs in the control and in the experimental condition differed systematically. The experimental PSEs were smaller when $t_{\mathrm{S}}=t_{\mathrm{P}}+40$ or $t_{\mathrm{P}}+80 \mathrm{~ms}$, indicating a robust occurrence of timeshrinking. This underestimation of $t_{\mathrm{S}}$, however, was replaced by overestimation, whose highest magnitude reached above $50 \mathrm{~ms}$, when $t_{\mathrm{S}} \geq t_{\mathrm{P}}+240 \mathrm{~ms}$ for all the $t_{\mathrm{P}}$ values. Thus, as in Experiment 1 , time-shrinking appeared when the difference between $t_{\mathrm{S}}$ and $t_{\mathrm{P}}$ was 40 or $80 \mathrm{~ms}$, and contrast of $t_{\mathrm{S}}$ to $t_{\mathrm{P}}$ took over when $t_{\mathrm{S}}$ was lengthened.

When $t_{\mathrm{P}}=160 \mathrm{~ms}$ as in Experiment 1, the overestimation again seemed to have a local peak when $t_{\mathrm{S}}=320 \mathrm{~ms}$. This tendency indeed seems interesting, but is an issue to be investigated in the future.

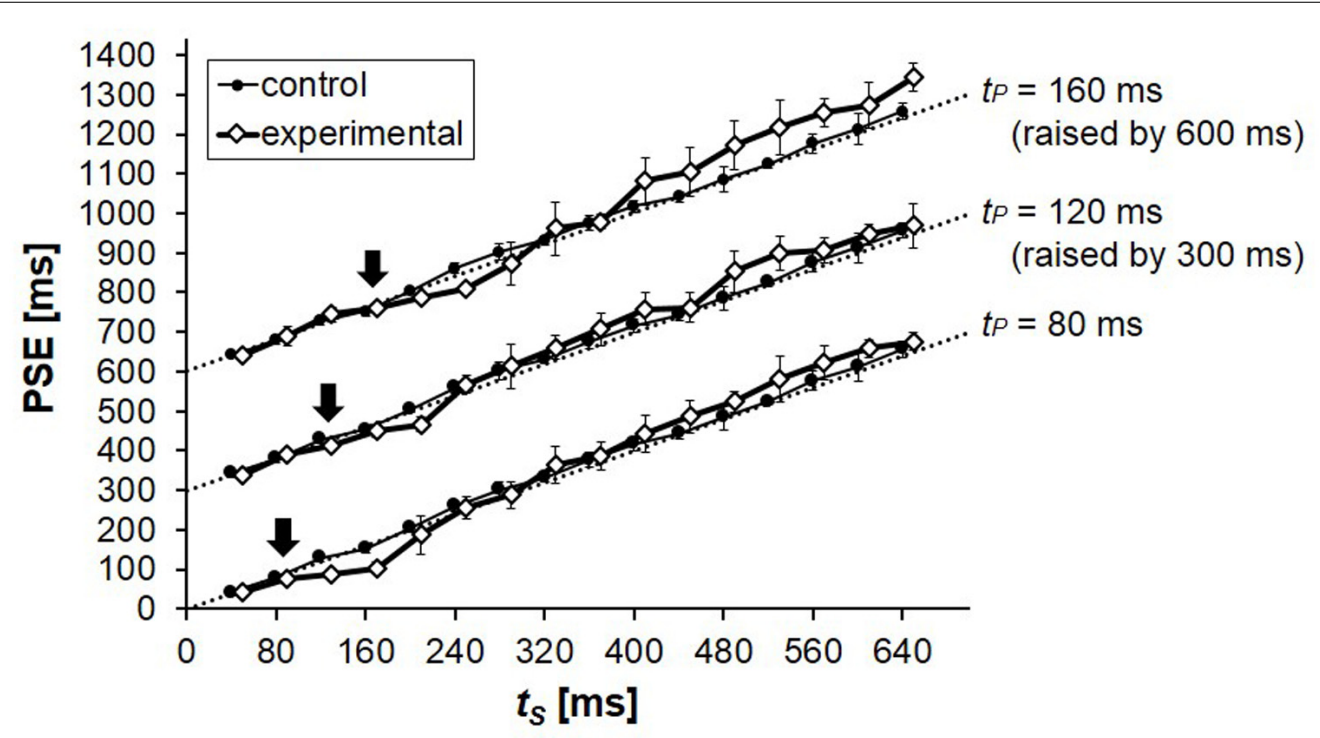

FIGURE 3 | Mean PSEs obtained from five participants in Experiment 2. PSE corresponds to the duration of $t_{\mathrm{C}}$ that was perceived to be equal to the duration of $t_{S}$. The results for $t_{\mathrm{P}}=120$ and $160 \mathrm{~ms}$ were raised by 300 and $600 \mathrm{~ms}$, respectively, in this graph for clarity. The physical values of ts (the points of objective equality) are indicated by dotted lines, on which tp values are indicated by arrows. Error bars represent standard deviations between participants. 
To test whether the common tendency in overestimation pattern across different $t_{\mathrm{p}}$ values (i.e., the underestimation of $t_{\mathrm{S}}$ when $t_{\mathrm{S}}=t_{\mathrm{P}}+40$ or $t_{\mathrm{P}}+80 \mathrm{~ms}$ and the overestimation when $t_{\mathrm{S}} \geq t_{\mathrm{P}}+240 \mathrm{~ms}$, observed for all $t_{\mathrm{P}}$ values) was statistically significant, we conducted a Friedman test utilizing the mean overestimation values for each $t_{\mathrm{P}}$ duration $(=80,120$, or $160 \mathrm{~ms})$. There was a statistically significant tendency in overestimation depending on the difference between the two neighboring intervals $\left(t_{\mathrm{S}}-t_{\mathrm{P}}=-40\right.$ to $\left.480 \mathrm{~ms}\right), \chi^{2}(13)=34.505, p=0.001$. As in Experiment 1, we also performed the same Friedman test without the conditions in which $t_{\mathrm{S}}-t_{\mathrm{P}}=40$ or $80 \mathrm{~ms}$, where timeshrinking should have taken place. The tendency in overestimation pattern was significant again, $\chi^{2}(11)=27.410, p=0.004$.

\section{EXPERIMENT 3}

Time-shrinking almost disappeared, although not completely, when $t_{\mathrm{P}}$ was above $300 \mathrm{~ms}$ (Nakajima et al., 2004, Figure 11). Our next step was to examine whether the tendency for $t_{\mathrm{S}}$ to be underestimated when $t_{\mathrm{S}}=t_{\mathrm{P}}+40$ or $t_{\mathrm{p}}+80 \mathrm{~ms}$ and overestimated when $t_{\mathrm{S}}$ was further lengthened, as observed in Experiments 1 and 2 , would appear entirely in the $t_{\mathrm{p}}$ range in which we could expect time-shrinking. Because the overestimation of $t_{\mathrm{S}}$ appeared in a very wide range of $t_{S}$ in Experiment 2, we made the range of $t_{S}$ in the present experiment even wider.

\section{METHODS}

\section{Participants}

Six students of Kyushu University, three males and three females, participated. Four of them had taken part in Experiment 2, but there had been an interval of at least 3 months. One of the participants had been educated to become a high-school music teacher, and four of them had received education for acoustic design, including basic training in music performance. The sixth one was an amateur musician who had been playing percussions for 8 years. They were 20-46 years old.

\section{Materials}

Duration markers and the way of presentation were the same as in Experiment 2. In the standard patterns of the experimental condition, $t_{\mathrm{P}} \mid t_{\mathrm{S}}, t_{\mathrm{P}}=40,120,200$, or $280 \mathrm{~ms}$, where time-shrinking had occurred clearly (Nakajima et al., 2004). Overestimation of $t_{S}$ had been recorded for these $t_{\mathrm{p}}$ values, but only in a handful of stimulus patterns, and only up to $30 \mathrm{~ms}$, except for Experiment 2 of the present article. The standard time interval, $t_{S}$, was varied from 40 to $1000 \mathrm{~ms}$ in steps of $80 \mathrm{~ms}$ both in the control and in the experimental condition. There were 65 stimulus patterns: 5 ( 1 control $+4 t_{\mathrm{p}}$ durations $) \times 13$ ( $t_{\mathrm{S}}$ durations $)$. The standard pattern was presented 1500-2500 ms after the participant initiated a presentation. There was an interval of 4000-5000 ms between the onsets of $t_{\mathrm{S}}$ and $t_{C}$.

\section{Procedure}

The participant performed two adjustment trials, one in ascending series and one in descending series, for each stimulus pattern, and thus 130 trials in total: 65 (stimulus patterns) $\times 2$ (series), which were arranged in random order and divided into 10 blocks of 13 measurement trials preceded by two warm-up trials. Before the measurement, the participant performed 15 training trials, for which representative stimulus patterns were employed. Thus, the whole experiment consisted of 14 blocks: 1 (training block) +13 (measurement blocks). Each block took around 15-30 min, and the whole experiment was carried out over a period of 2-3 days for each participant.

\section{RESULTS AND DISCUSSION}

We performed a two-way [condition $\left(1\right.$ control $+4 t_{\mathrm{P}}$ durations $) \times t_{S}$ duration] ANOVA utilizing the PSE values. The main effect of condition ( 1 control $+4 t_{\mathrm{p}}$ durations) was significant, $F(4,20)=6.450, p<0.01, \eta_{p}^{2}=0.563$, and so was the interaction between condition ( 1 control $+4 t_{\mathrm{P}}$ durations $)$ and $t_{\mathrm{S}}$ duration, $F(48,240)=2.539, p<0.01, \eta_{\mathrm{p}}^{2}=0.337$.

The PSEs in the control condition were very close to the physical values of $t_{\mathrm{S}}$ (Figure 4). Although slight deviations appeared again systematically, they were almost unrecognizable in the graphs except for the longest $t_{\mathrm{S}}$ values, for which PSEs tended to be slightly shorter than the corresponding points of objective equality.

The PSEs in the control and in the experimental condition differed systematically. The experimental PSEs were conspicuously smaller when $t_{\mathrm{S}}=t_{\mathrm{P}}+80 \mathrm{~ms}$, again showing the robustness of time-shrinking. For $t_{\mathrm{P}}=120,200$, and $280 \mathrm{~ms}$, the underestimation of $t_{\mathrm{S}}$ was replaced by overestimation when $t_{\mathrm{S}}$ was longer. When $t_{\mathrm{S}}>t_{\mathrm{P}}+240 \mathrm{~ms}$, the PSEs in the experimental condition were never smaller than those in the control condition. For $t_{\mathrm{P}}=200$ and $280 \mathrm{~ms}$, the overestimation reached above $100 \mathrm{~ms}$, which is comparable to the temporal illusions Israeli (1930) reported in the visual modality. For $t_{\mathrm{P}}=40 \mathrm{~ms}$, no clear overestimation appeared. When the same preceding interval duration was employed in Nakajima et al.'s (2004) Experiment 1, however, some overestimation appeared stably, although the amount was only about $10 \mathrm{~ms}$, and it would be safer to reserve any clear conclusion for this $t_{\mathrm{P}}$ value. In the present experiment, time-shrinking

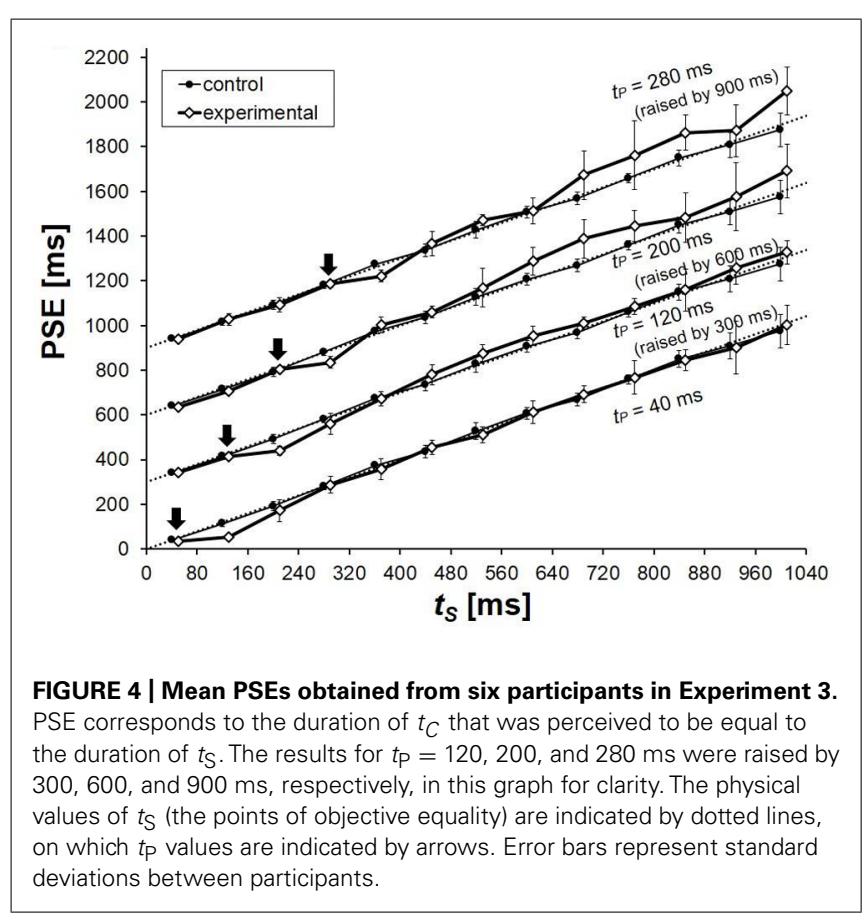


appeared when the difference between $t_{\mathrm{S}}$ and $t_{\mathrm{P}}$ was $80 \mathrm{~ms}$, and contrast of $t_{\mathrm{S}}$ to $t_{\mathrm{P}}$ took over when $t_{\mathrm{S}}$ was lengthened except when $t_{\mathrm{P}}=40 \mathrm{~ms}$.

As in Experiment 2, we conducted a Friedman test utilizing the mean overestimation values for each $t_{\mathrm{p}}$ duration to examine whether the common tendency in the overestimation pattern across different $t_{\mathrm{P}}$ values $40,120,200$, and $280 \mathrm{~ms}$ was statistically significant. There was a statistically significant tendency in overestimation depending on the difference between the two neighboring intervals $\left(t_{\mathrm{S}}-t_{\mathrm{P}}=0-720 \mathrm{~ms}\right), \chi^{2}(9)=25.855$, $p=0.002$. We also performed the same Friedman test, but without the (negative) overestimations in conditions in which $t_{\mathrm{S}}-t_{\mathrm{P}}=80 \mathrm{~ms}$, where time-shrinking should have taken place. The tendency in overestimation pattern was significant again, $\chi^{2}(8)=19.600, p=0.012$, confirming that the overestimation patterns had a common tendency even when the influence of time-shrinking (the dip at $t_{\mathrm{S}}-t_{\mathrm{P}}=80 \mathrm{~ms}$ ) was cancelled.

\section{EXPERIMENT 4}

The overestimation of $t_{S}$ took place to a remarkable degree in Experiments 1-3. It seemed necessary to have some idea on whether this strong contrast, which was observed between the two neighboring time intervals, $t_{1}$ and $t_{2}$ in this order, for the perception of $t_{2}$, also affected the perception of $t_{1}$. Because timeshrinking was a unilateral illusion affecting mainly the perception of $t_{2}$, we first examined whether, and if so how, the underestimation of $t_{2}$ gave way to overestimation, and this indeed happened to a remarkable degree. Now it seemed important to check whether this contrast was unilateral or bilateral. In the present study, we just conducted an experiment to be appended to Experiment 3, but this would help us to interpret the present results. We picked up six temporal patterns of two neighboring time intervals in which contrast between them had caused overestimation of $t_{2}\left(t_{S}\right.$ in Experiment 3$)$. Then PSEs of $t_{1}$ were measured for these patterns. For example, we took up a pattern of $t_{1}=200 \mathrm{~ms}$ and $t_{2}=680 \mathrm{~ms}$, in which $t_{2}$ had been overestimated by more than $100 \mathrm{~ms}$ in Experiment 3. In the present experiment, we were interested in whether or not the same mechanism of contrast (bilaterally) led to the underestimation of $t_{1}$ making its PSE shorter than the control value. Because $t_{1}$ was the standard time interval, it is called $t_{S}$, and the succeeding time interval $t_{2}$ is called $t_{\mathrm{SUC}}$ in the present report. In other words, we used the same temporal patterns of two neighboring time intervals marked by three successive sounds as in Experiment 3, and the key difference was that $t_{C}$ was adjusted to match the perceived duration of the first interval instead of that of the second interval.

Due to the unavailability of a certain potential participant, we decided to employ five of the six participants from Experiment 3, making it still possible to reuse the data in the control condition of Experiment 3.

\section{METHODS}

\section{Participants}

Five students, three males and two females, participated in this experiment after participating in Experiment 3. There had been an interval of at least 1 month between these experiments. They were 21-25 years old. Four of them had taken part in Experiment 2, but there had been an interval of at least 3 months. Four of them had received education for acoustic design, including basic training in music performance. The fifth one was an amateur musician who had been playing percussions for 8 years.

\section{Materials}

Six stimulus patterns were chosen from the stimulus patterns in Experiment 3. In the standard patterns of the experimental condition, $t_{\mathrm{S}} \mid t_{\mathrm{SUC}}$, the standard time interval, $t_{\mathrm{S}}$, was 120,200 , or $280 \mathrm{~ms}$; these values had been chosen for $t_{\mathrm{P}}$ in Experiment 3 . The control patterns of these $t_{\mathrm{S}}$ values in Experiment 3 were regarded as the virtual control patterns of the present experiment, and thus the control data of the present participants were reused. The succeeding time interval, $t_{\text {SUC }}$, was 440 or $680 \mathrm{~ms}$; tsUC in any stimulus pattern would have been overestimated stably if it had been the standard time interval. There were six stimulus patterns not including the virtual control patterns. The standard pattern was presented 1500-2500 ms after the participant initiated a presentation. There was a silence of 4000-5000 ms between the onsets of $t_{S}$ and $t_{C}$.

\section{Procedure}

The participant performed two adjustment trials, one in ascending series and one in descending series, for each stimulus pattern, and thus 12 trials in total arranged in random order. Four trials were conducted first for training and a warm-up, and the measurement trials followed without a break. The experiment took around $20 \mathrm{~min}$.

\section{RESULTS AND DISCUSSION}

We performed a two-way [condition $\left(1\right.$ control $+2 t_{\text {SUC }}$ durations $) \times t_{S}$ duration] ANOVA utilizing the PSE values. Neither the main effect of condition ( 1 control $+2 t_{\text {SUC }}$ durations $)$ nor the interaction between condition ( 1 control $+2 t_{\text {SUC }}$ durations $)$ and $t_{\mathrm{S}}$ duration was significant, $F(2,8)=0.222, p>0.05, \eta_{\mathrm{p}}^{2}=0.052$; $F(4,16)=2.740, p>0.05, \eta_{\mathrm{p}}^{2}=0.407$, respectively.

The PSEs in the control condition were almost equal to the physical values of $t_{S}$ (Figure 5). The PSEs in the control and in the experimental condition were very close to each other. Underestimation of $t_{\mathrm{S}}$ that should have occurred if the systematic contrast in Experiment 3 were bilateral did not take place to any observable degree. Although we do not have sufficient data to conclude that the systematic contrast observed in Experiments 1, 2, and 3 was unilateral, the underestimation of $t_{\mathrm{S}}$ was almost negligible even in conditions in which the mechanism of contrast must have worked clearly. The observed contrast was at least very close to unilateral.

\section{GENERAL DISCUSSION}

The purpose of the present study was to observe the overestimation of an empty time interval caused by a preceding time interval. The conditions in the present study were comparable to the conditions in which time-shrinking had been reported to take place. We had assumed that time-shrinking was a unilateral perceptual assimilation of an empty time interval to a shorter preceding time interval. One may wonder whether the potential rhythmic regularity of presented patterns may be playing a 


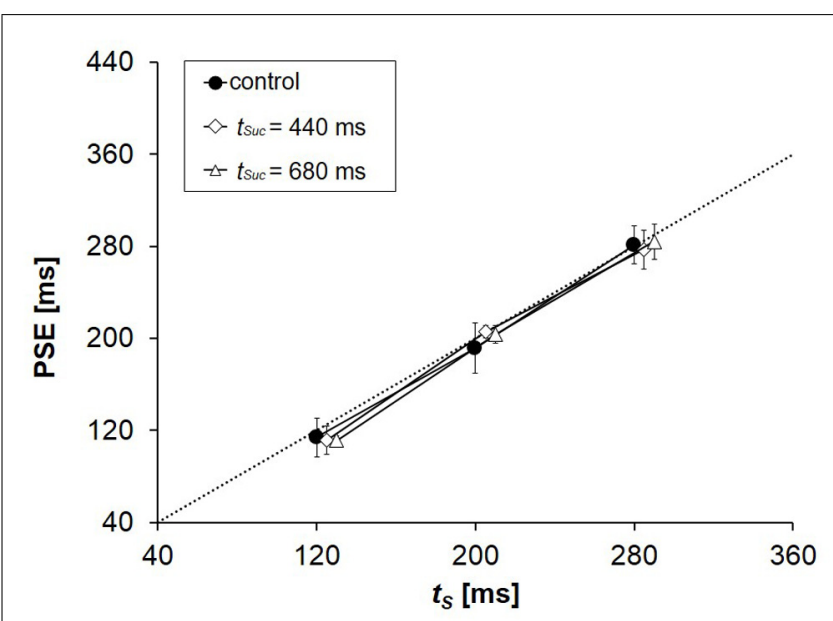

FIGURE 5 | Mean PSEs obtained from five participants in

Experiment 4. PSE corresponds to the duration of $t_{C}$ that was perceived to be equal to the duration of $t_{S}$. Some dots are deviated slightly from the scale marks on the horizontal axis to avoid being invisible in the graph. The physical values of $t_{S}$ (the points of objective equality) are indicated by a dotted line. Error bars represent standard deviations between participants.

crucial role, but this idea is not supported by the fact that timeshrinking took place even when the preceding time interval and the time interval to be judged were separated in time (Sasaki et al., 2002). The assumption of "assimilation" itself is not related to any particular perceptual mechanism directly, but it can give us a wider view of the observed facts. Because perceptual assimilation and contrast often appear in the same context, we examined whether a change from the unilateral assimilation, time-shrinking, could give way to contrast when the difference between the neighboring time intervals was increased. The range of the first time interval that can cause time-shrinking has been determined systematically in previous studies, and it has been established that the illusion takes place only when the difference between the neighboring time intervals was smaller than $\sim 100 \mathrm{~ms}$. This knowledge made it possible for us to focus onto the stimulus conditions in which contrast was likely to take place. As a result, overestimation of the second of the neighboring time intervals appeared systematically.

When $t_{\mathrm{P}}$ precedes and neighbors $t_{\mathrm{S}}$ causing time-shrinking (i.e., the systematic underestimation of $t_{\mathrm{S}}$ ), an overestimation of $t_{\mathrm{S}}$ was observed when $t_{\mathrm{S}}$ was lengthened. The only exception was when $t_{\mathrm{P}}$ was set to be extremely short, i.e., $t_{\mathrm{P}}=40 \mathrm{~ms}$. The overestimation of $t_{\mathrm{S}}$ never disappeared when $t_{\mathrm{S}}-t_{\mathrm{P}}>240 \mathrm{~ms}$ for the other $t_{\mathrm{P}}$ values. The overestimation as a function of $t_{\mathrm{S}}-t_{\mathrm{P}}$ showed a common tendency across the different $t_{\mathrm{p}}$ values (Figure 6), which was confirmed by the Friedman tests.

What we had not expected was that the contrast appeared in such a wide range and to such a large degree. About the range of the second time interval, we have already reached $1 \mathrm{~s}$ as the longest duration. It will be very important in the future to determine the upper limit of the range in which the overestimation takes

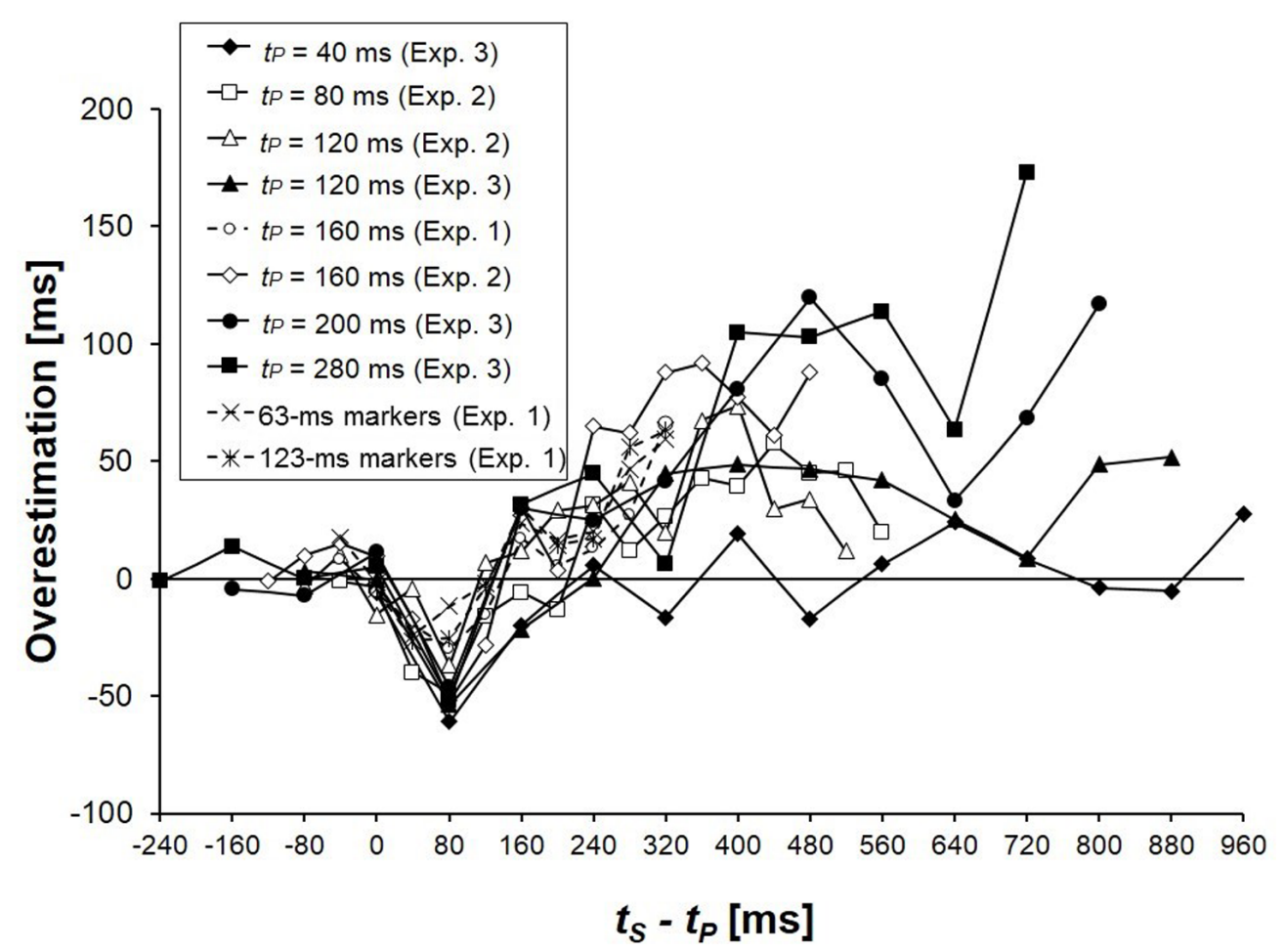

FIGURE 6 | Overestimations of $\boldsymbol{t}_{\mathbf{S}}$ as functions of $\boldsymbol{t}_{\mathbf{S}}-\boldsymbol{t}_{\mathrm{P}}$ in Experiments $\mathbf{1 , 2}$, and 3. The overestimations were calculated as the increases of PSES due to the presence of $t_{\mathrm{p}}$. 
place, but this would require a new experimental paradigm because we can easily reach the perceptual limit; when a time interval is equal to or above $1.5-2 \mathrm{~s}$, it is often difficult to grasp the whole interval perceptually, or to perceive it as a part of a single rhythm pattern (Fraisse, 1978; Nakajima et al., 1980; Warren, 2008; see also Grondin, 2012 for a perceptual limit at around $1.5 \mathrm{~s}$ ).

The amount of the overestimation sometimes surpassed $100 \mathrm{~ms}$. Although similar overestimation had appeared occasionally in previous studies on unilateral or bilateral assimilation between neighboring time intervals, the positive overestimation had never reached $40 \mathrm{~ms}$ except in the present Experiment 1. It turned out now that the overestimation can be larger than time-shrinking in terms of deviation from the control PSEs in milliseconds. Although we had (re)started this study as something to be added to the studies of perceptual assimilation between time intervals, the overestimation of the second time interval now appeared as a phenomenon worth investigating more systematically in different series of studies. It is particularly necessary to examine whether the present results can be related to the fact that a successive presentation of two objects (as would be inevitable for time intervals) could facilitate the perceptual contrast between them (Ikeda and Obonai, 1955).

Fraisse $(1978,1982)$ argued that rhythm patterns were often based on two dominant duration values, and that they were mostly in a ratio 1:2, and occasionally in 1:3; in Western music, the shorter durations were typically $150-290 \mathrm{~ms}$, and the longer durations 300-900 ms. This could explain the overestimation in the present study in some cases. Perceptual contrast can often take place as, or as a result of, categorical perception, although it is often difficult to relate results in different paradigms (Repp and Liberman, 1987). If a shorter duration and a longer duration neighboring each other are to be perceived as in different perceptual categories, i.e., in the short-duration category and in the long-duration category, this can be an aspect, or a cause, of perceptual contrast. In the present experiments, the first time interval was always below $290 \mathrm{~ms}$, and the second time interval was mostly above $300 \mathrm{~ms}$ when it was overestimated. Most cases in which $t_{\mathrm{p}}$ caused the overestimation of $t_{\mathrm{S}}$ can be interpreted by the fact that $t_{\mathrm{p}}<300<t_{\mathrm{S}} \mathrm{ms}$, which should have caused the time intervals to be relocated in different perceptual categories, which then should have led to the overestimation of $t_{s}$. This interpretation describes the general tendency of the present data rather well, and is worth investigating further. However, the categorical boundary at about $300 \mathrm{~ms}$ is hardly a part of common knowledge, and a systematic investigation on this issue should be the first thing necessary to pursue this path.

Another possible explanation related to a categorical aspect of temporal perception is related to the studies of Miyauchi and Nakajima (2005) and ten Hoopen et al. (2006; see also Sasaki et al., 1998; and Miyauchi and Nakajima, 2007). They presented auditory temporal patterns as used in the present experiments to participants, and established a 1:1 category, i.e., a perceptual category in which the neighboring time intervals are perceived as equal to each other even when the physical difference between them is greater than the differential limen. One of the boundaries of this category was very close to the point at which time-shrinking reaches its maximum, i.e., the point at which $t_{S}-t_{\mathrm{p}} \simeq 80 \mathrm{~ms}$; the overestimation of ts typically appeared when the difference between $t_{\mathrm{p}}$ and $t_{\mathrm{S}}$ doubled this value. This is an idea to be kept for future research, but some difficulty arises if we are to explain why the contrast appeared not immediately when the 1:1 category gave way but when the difference between $t_{\mathrm{p}}$ and $t_{\mathrm{S}}$ increased further.

Although human listeners are able to discriminate temporal patterns more precisely than specified by musical notations, they tend to establish perceptual categories represented by simple ratios between neighboring durations as in musical notations (Honing, 2013; see also Povel, 1981). It is understandable that humans have to categorize temporal patterns in order to memorize, imitate, or respond quickly to them. This might lead to the human listeners' tendency to make the subjective ratios between neighboring durations closer to those in the prototypical patterns, which are made of simple ratios. As Fraisse $(1978,1982)$ indicated, the perceptual system tends to make the perceived ratio closer to a simple integral ratio as 1:1 or 1:2 (see also Honing, 2013). Supporting this observation, Nakajima (1979) reported that a pattern of two neighboring time intervals of 80 and $160 \mathrm{~ms}$ was perceived in ratios close to 1:1 or 1:2 avoiding intermediate cases, and Povel (1981) systematically showed the stability of the ratio 1:2 in a task to reproduce repeated temporal patterns. It is very likely that a temporal pattern to be perceived as in a ratio 1:1.7, for example, is perceptually distorted to be closer to $1: 2$, causing the overestimation of the second time interval. However, this alone cannot account for the overestimation observed in the present study. Suppose that $t_{\mathrm{P}}=200 \mathrm{~ms}$ in the paradigm of Experiments 1,2, and 3. Nakajima et al. (1988, Table 1) showed that the temporal pattern $2001400 \mathrm{~ms}$ was perceived in a ratio 1:1.78, i.e., closer to 1:1 than the physical ratio 1:2, and this tendency was in line with their psychophysical hypothesis. If the perceptual system tries to shift toward a simpler ratio $1: 2$, then the second time interval may be overestimated. Although this hypothesis seemed attractive, a further examination of our own data was not very promising. For example, in the pattern $2001520 \mathrm{~ms}$ in Experiment 3, which would correspond to a subjective ratio 1:2.14 according to Nakajima et al.'s (1988) psychophysical hypothesis, the second time interval should be underestimated to make the subjective ratio closer to 1:2. In reality, this pattern still caused the overestimation of $t_{\mathrm{s}}$. As in this example, the overestimation took place more widely than was predicted from the perceptual system's tendency toward simpler ratios. No literature or experimental data are within the present authors' knowledge about the mechanism to show such perceptual tendencies, and the present experimental paradigm will be useful to solve this problem in the future. It should also be interesting for future research to examine the assimilation and contrast in a more complex context (e.g., Jones and McAuley, 2005).

One may wonder whether the overestimation of $t_{S}$ in the present results can be explained by time-order error (TOE), which is a phenomenon observed in psychophysics in general. Previous studies reported that TOE is expected to be positive for short durations of a few hundred milliseconds, as the durations utilized as $t_{\mathrm{p}}$ in the present experiment (although it should be noted that in TOE studies two successive and distinct intervals are used instead of two intervals sharing a common marker; Woodrow, 1951; Eisler et al., 2008). This means that the duration of tp should be overestimated 
relative to $t_{S}$. In the present experiments, $t_{S}$ was overestimated (Experiments 1-3) but $t_{\mathrm{P}}$ was not (Experiment 4). It seems difficult to explain the tendencies of the present results with TOEs as reported in classical literature (e.g., Hellström, 1985).

We began the present study in order to observe what would happen if the temporal patterns causing time-shrinking were modified by lengthening the second of the two neighboring time intervals. This tactic worked well to find clear cases in which assimilation gave way to contrast. As the overestimation was so systematic, however, it will be necessary in the future to investigate this issue in a broader paradigm apart from time-shrinking. First, it is of some interest whether the first of the neighboring time intervals is also affected when the second time interval is overestimated. The results of Experiment 4 were negative, suggesting that the contrast was unilateral, but we need further studies on this point. It attracts our interest as well whether any perceptual contrast would take place if the temporal order between the longer and the shorter time interval is reversed. Although there are some previous data for some speculation, we basically need a new set of experiments.

Arao et al. (2000) showed that time-shrinking occurred also in the visual modality, and it took place when the neighboring time intervals $t_{\mathrm{P}}$ and $t_{\mathrm{S}}$, in this order, had the relationship $t_{\mathrm{P}}<t_{\mathrm{S}}$ $<\sim 1.8 \times t_{\mathrm{p}}$. If we see their data from the present viewpoint, it is suggested that overestimation of $t_{\mathrm{S}}$ is likely to replace timeshrinking if $t_{\mathrm{S}}$ is far above this range, and this is worth investigating immediately. The same argument may hold also for the tactile modality (Hasuo et al., 2014).

One big problem for our future research is that the experimental data are not always very stable in the present paradigm, and this can be the case in other related paradigms. The individual differences were sometimes as big as the effects to be investigated. Fortunately, our present purpose was simple, i.e., to examine whether systematic overestimation of the second time interval would or would not appear; we somehow reached tentative conclusions. If the many issues suggested here are to be investigated in the future, however, we will need more sophisticated methods. One possible solution is to design experiments that enable us to perform some multivariate analyses. Another possibility is to obtain a lot of data from a few participants, and to compare results in different conditions for each individual participant.

We investigated the perception of empty time intervals marked by tone bursts, and employed temporal patterns of two neighboring time intervals. Our research question was whether the overestimation of the second time interval would replace the underestimation (time-shrinking) if the difference between the neighboring time intervals was increased. The overestimation took place very systematically when the first time interval was 80-280 ms, and its amount sometimes exceeded $100 \mathrm{~ms}$, indicating that this was an important phenomenon related to rhythm perception. It is very likely that similar temporal patterns appear often in music. Assimilation and contrast, which Fraisse (1978) considered to be two important principles to construct rhythm, were manifested in an in vitro situation.

\section{ACKNOWLEDGMENTS}

This work was supported by the Japan Society for the Promotion of Science [Grants-in-Aid for Scientific Research S (19103003) and
A (25242002) to Yoshitaka Nakajima, and a Grant-in-Aid for JSPS Fellows (25-6091) to Emi Hasuo], and its final stage was a part of Kyushu University Interdisciplinary Programs in Education and Projects in Research Development (The Kyushu University Project for Interdisciplinary Research of Perception and Cognition).

\section{REFERENCES}

Arao, H., Suetomi, D., and Nakajima, Y. (2000). Does time-shrinking take place in visual temporal patterns? Perception 29, 819-830. doi: 10.1068/p2853

de Saussure, F. (1966). Course in General Linguistics. eds C. Bally and A. Sechehaye in collaboration with A. Riedlinger, Trans. W. Baskin. New York: McGraw-Hill.

Eisler, H., Eisler, A. D., and Hellström, Å. (2008). "Psychophysical issues in the study of time perception," in Psychology of Time, ed. S. Grondin (Bingley: Emerald), 75-109.

Fraisse, P. (1978). "Time and rhythm perception," in Handbook of Perception Volume? Perceptual Coding, ed. E. C. Carterette and M. P. Friedman (New York: Academic press), 203-254.

Fraisse, P. (1982). "Rhythm and tempo," in The Psychology of Music, ed. D. Deutsch (New York: Academic Press), 149-180. doi: 10.1016/B978-0-12-213562-0. 50010-3

Grondin, S. (2012). Violation of the scalar property for time perception between 1 and 2 seconds: evidence from interval discrimination, reproduction, and categorization. J. Exp. Psychol. Hum. Percept. Perform. 38, 880-890. doi: $10.1037 / \mathrm{a} 0027188$

Hamburger, K. (2005). Color assimilation as a grouping factor. Gestalt Theory 27, 155-163.

Hasuo, E., Kuroda, T., and Grondin, S. (2014). About the time-shrinking illusion in the tactile modality. Acta Psychol. 147, 122-126. doi: 10.1016/j.actpsy.2013. 06.007

Hasuo, E., Nakajima, Y., and Hirose, Y. (2011). Effects of sound marker durations on rhythm perception. Perception 40, 220-242. doi: 10.1068/p6846

Hasuo, E., Nakajima, Y., Osawa, S., and Fujishima, H. (2012). Effects of temporal shapes of sound markers on the perception of interonset time intervals. Atten. Percept. Psychophys. 74, 430-445. doi: 10.3758/s13414-011-0236-1

Hellström, $\AA$. (1985). The time-order error and its relatives: mirrors of cognitive processes in comparing. Psychol. Bull. 97, 35-61. doi: 10.1037/0033-2909.97.1.35 Helson, H. (1963). Studies of anomalous contrast and assimilation. J. Opt. Soc. Am. 53, 179-184. doi: 10.1364/JOSA.53.000179

Helson, H. (1964). Adaptation-Level Theory: An Experimental and Systematic Approach to Behavior. New York: Harper \& Row.

Honing, H. (2013). "Structure and interpretation of rhythm in music," in The Psychology of Music, 3rd Edn, ed. D. Deutsch (San Diego, CA: Academic Press), 369-404.

Ikeda, H., and Obonai, T. (1955). The studies of figural after-effects: IV. The contrastconfluence illusion of concentric circles and the figural after-effect. Jpn. Psychol. Res. 2, 17-23.

Israeli, N. (1930). Illusions in the perception of short time intervals. Arch. Psychol. $19,1-47$.

Jones, M. R., and McAuley, J. D. (2005). Time judgments in global temporal contexts. Percept. Psychophys. 67, 398-417. doi: 10.3758/BF03193320

King, D. (1988). Assimilation is due to one perceived whole and contrast is due to two perceived wholes. New Ideas Psychol. 6, 277-288. doi: 10.1016/0732$118 X(88) 90039-6$

Koffka, K. (1935). Principles of Gestalt Psychology. London: Bradford.

McKenna, F. P. (1984). Assimilation and contrast in perceptual judgments. Q. J. Exp. Psychol. 36, 531-548. doi: 10.1080/14640748408402176

Miyauchi, R., and Nakajima, Y. (2005). Bilateral assimilation of two neighboring empty time intervals. Music Percept. 22, 411-424. doi: 10.1525/mp.2005.22.3.411

Miyauchi, R., and Nakajima, Y. (2007). The category of 1:1 ratio caused by assimilation of two neighboring empty time intervals. Hum. Mov. Sci. 26, 717-727. doi: 10.1016/j.humov.2007.07.008

Morinaga, S., and Noguchi, K. (1966). An attempt to unify the size-assimilation and size-contrast illusions. Psychol. Forsch. 29, 161-168. doi: 10.1007/BF00510815

Nakajima, Y. (1979). A psychophysical investigation of divided time intervals shown by sound bursts. J. Acoust. Soc. Jpn. 35, 145-151.

Nakajima, Y., Nishimura, S., and Teranishi, R. (1988). Ratio judgments of empty durations with numeric scales. Perception 17, 93-118. doi: 10.1068/p170093 
Nakajima, Y., Shimojo, S., and Sugita, Y. (1980). On the perception of two successive sound bursts. Psychol. Res. 41, 335-344. doi: 10.1007/BF003 08878

Nakajima, Y., Ten Hoopen, G., Sasaki, T., Yamamoto, K., Kadota, M., Simons, M., et al. (2004). Time-shrinking: the process of unilateral temporal assimilation. Perception 33, 1061-1079. doi: 10.1068/p5061

Nakajima, Y., Ten Hoopen, G., and van der Wilk, R. (1991). A new illusion of time perception. Music Percept. 8, 431-448. doi: 10.2307/402 85521

Povel, D.-J. (1981). Internal representation of simple temporal patterns. J. Exp. Psychol. Hum. 7, 3-18. doi: 10.1037/0096-1523.7.1.3

Repp, B. H., and Liberman, A. M. (1987). "Phonetic category boundaries are flexible," in Categorical Perception: The Groundwork of Cognition, ed. S. Harnad (New York: Cambridge University Press), 89-112.

Sasaki, T., Nakajima, Y., and ten Hoopen, G. (1998). Categorical rhythm perception as a result of unilateral assimilation in time-shrinking. Music Percept. 16, 201-222.

Sasaki, T., Suetomi, D., Nakajima, Y., and Ten Hoopen, G. (2002). Time-shrinking, its propagation, and Gestalt principles. Percept. Psychophys. 64, 919-931. doi: 10.3758/BF03196796

Shapley, R., and Reid, R. C. (1985). Contrast and assimilation in the perception of brightness. Proc. Natl. Acad. Sci. U.S.A. 82, 5983-5986. doi: 10.1073/pnas.82.17.5983

Shigeno, S. (1991). Assimilation and contrast in the phonetic perception of vowels. J. Acoust. Soc. Am. 90, 103-111. doi: 10.1121/1.401303

Siegel, S., and Castellan, N. J. (1988). Nonparametric Statistics for the Behavioral Sciences, 2nd Edn. New York: McGraw-Hill. ten Hoopen, G., Sasaki, T., Nakajima, Y., Remijn, G. B., Massier, B., Rhebergen, K. S., et al. (2006). Time-shrinking and categorical temporal ratio perception: evidence for a 1:1 temporal category. Music Percept. 24, 1-22. doi: 10.1525/mp.2006.24.1.1

Warren, R. (2008). Auditory Perception: An Analysis and Synthesis, 3rd Edn. New York: Cambridge University Press. doi: 10.1017/CBO9780511754777

Woodrow, H. (1951). “Time Perception," in Handbook of Experimental Psychology, ed. S. S. Stevens (New York: John Wiley \& Sons), 1224-1236.

Yamashita, M., and Nakajima, Y. (1999). "The effect of marker duration on timeshrinking," in Music, Mind and Science, ed. S. W. Yi (Seoul: Seoul National University Press), 211-218.

Conflict of Interest Statement: The authors declare that the research was conducted in the absence of any commercial or financial relationships that could be construed as a potential conflict of interest.

Received: 21 February 2014; accepted: 16 April 2014; published online: 14 May 2014. Citation: Nakajima Y, Hasuo E, Yamashita M and Haraguchi Y (2014) Overestimation of the second time interval replaces time-shrinking when the difference between two adjacent time intervals increases. Front. Hum. Neurosci. 8:281. doi: 10.3389/fnhum. 2014.00281

This article was submitted to the journal Frontiers in Human Neuroscience.

Copyright (c) 2014 Nakajima, Hasuo, Yamashita and Haraguchi. This is an openaccess article distributed under the terms of the Creative Commons Attribution License (CC BY). The use, distribution or reproduction in other forums is permitted, provided the original author(s) or licensor are credited and that the original publication in this journal is cited, in accordance with accepted academic practice. No use, distribution or reproduction is permitted which does not comply with these terms. 